\title{
TECNOLOGIAS DIGITAIS NA EDUCAÇÃO INFANTIL: REPRESENTAÇÕES SOCIAIS DE PROFESSORAS
}

\section{LAS TECNOLOGÍAS DIGITALES EN LA EDUCACIÓN DE LA PRIMERA INFANCIA: REPRESENTACIONES SOCIALES DE LAS PROFESORAS}

\author{
DIGITAL TECHNOLOGIES IN EARLY CHILDHOOD EDUCATION: SOCIAL \\ REPRESENTATIONS OF FEMALE TEACHERS
}

\author{
Nedia Maria de OLIVEIRA ${ }^{1}$ \\ Simão Pedro Pinto MARINHO ${ }^{2}$
}

RESUMO: Esse artigo apresenta os resultados de uma pesquisa que buscou identificar as representações sociais de professoras sobre as tecnologias digitais de informação e comunicação (TDIC) na prática pedagógica na Educação Infantil. A pesquisa, com abordagem mista, foi realizada junto a professoras de escolas públicas de uma cidade de Minas Gerais e os dados foram analisados na perspectiva da teoria das representações sociais. Verificou-se que as professoras reconhecem a influência das TDIC na transformação do cotidiano das crianças. Percebem as tecnologias como capazes de despertar o interesse das crianças e de transformar sua forma de pensar, agir e interpretar o mundo, o que se acaba por refletir no contexto da educação infantil. Embora usuárias cotidianas das TDIC na vida pessoal, as professoras reconhecem dificuldades para incorporá-las em suas práticas pedagógicas na Educação Infantil, principalmente por não se sentirem para isso preparadas.

PALAVRAS-CHAVE: Representação social. Educação infantil. Professor. Tecnologias digitais de informação e comunicação.

RESUMEN: Este artículo presenta los resultados de una investigación que buscó identificar las representaciones sociales de los docentes sobre las tecnologías digitales de información y comunicación (TDIC) en la práctica pedagógica en la educación de la primera infancia. Con este fin, se desarrolló en un enfoque cualitativo y cuantitativo con los docentes de la Red de Educación Municipal de Minas Gerais, y los datos se analizaron desde la perspectiva de la teoría de las representaciones sociales. Se descubrió que los maestros reconocen la influencia de TDIC en la transformación de la vida cotidiana de los niños. Perciben que las tecnologías son capaces de despertar el interés de los niños y transformar su forma de pensar, actuar e interpretar el mundo, que finalmente se refleja en el contexto de la educación de la primera infancia. Aunque los usuarios cotidianos de TDIC en sus vidas personales, los maestros reconocen las dificultades para incorporarlos a sus prácticas

\footnotetext{
${ }^{1}$ Pontifícia Universidade Católica de Minas Gerais (PUC Minas), Belo Horizonte - MG - Brasil. Doutoranda no Programa de Pós-graduação em Educação. ORCID: http://orcid.org/0000-0003-1327-2163. E-mail: nedia@mgconecta.com.br

${ }^{2}$ Pontifícia Universidade Católica de Minas Gerais (PUC Minas), Belo Horizonte - MG - Brasil. Professor Titular no Programa de Pós-graduação em Educação. Doutorado em Educação (PUC-SP). ORCID: http://orcid.org/0000-0003-2382-4697.E-mail: marinhos@pucminas.br
} 
pedagógicas en la educación de la primera infancia, principalmente porque no se sienten preparados para ello.

PALABRAS CLAVE: Representación social. Educación infantil. Maestro. Tecnologías digitales de información y comunicación.

ABSTRACT: This article presents the results of a research that aimed to identify the social representations of teachers about digital information and communication technologies (TDIC) in the pedagogical practice in early childhood education. The research had a o this end, it was developed in a qualitative and quantitative approach with teachers of public schools in the state of Minas Gerais and the data were analyzed from the perspective of the theory of social representations. It was found that teachers recognize the influence of ICDT in the transformation of children's daily lives. They perceive technologies as capable of arousing the interest of children and transforming their way of thinking, acting and interpreting the world, which is eventually reflected in the context of early childhood education. Although everyday users of ICDT in their personal lives, teachers recognize difficulties in incorporating them into their pedagogical practices in early childhood education, mainly because they do not feel prepared for it.

KEYWORDS: Social representation. Early childhood education. Teacher. Digital Information and communication technologies.

\section{Introdução}

No contexto atual das sociedades evidencia-se a presença das tecnologias digitais de informação e comunicação, TDIC, (MARINHO, 2014) no cotidiano das pessoas, com influências significativas sobre quase todos os segmentos do agir humano, reconfigurando práticas, e do saber social. A velocidade de produção e divulgação de novos conhecimentos, devido ao uso das tecnologias digitais, determina a necessidade de uma nova escola, na qual haverá de se considerar uma educação para o mundo digital, com as decorrentes transformações sociais. A escola muda "se adaptando à medida que as tecnologias e os valores culturais interagem continuamente entre si” (ROBINSON; ARONICA, 2019, p. 64).

Pérez Gómez (2015, p. 28) é enfático:

Já não se pode entender os processos de ensino e aprendizagem, nos quais as pessoas se colocam em contato com a informação e o conhecimento disponível, sem a presença poderosa e amigável das tecnologias de informação e comunicação.

Acredita-se na necessidade da integração das TDIC no contexto educacional uma vez que possibilita significar novas formas e experiências de ensino e de aprendizagem, novas maneiras de se construir conhecimento e de se relacionar com o saber, contribuindo para a 
construção de competências. No contexto educacional infantil, no qual a criança é percebida como sujeito social, histórico e participante ativa no processo de construção do conhecimento, um novo olhar sobre o processo de ensino e de aprendizagem se impõe. Estudos de diversos teóricos, como Jean Piaget (1896-1980), Lev Vygotsky (1896- 1934), Henri Wallon (18791962) e David Ausubel (1918-2008), e estudos da Neurociência postulam que o desenvolvimento do cérebro decorre da integração entre o sujeito e o meio social, ou seja, da interação da criança com outras crianças, com adultos e com os mais variados recursos disponibilizados no meio social, dentre eles certamente as TDIC.

Para Amante (2003) a familiarização da criança, desde pequena, com as tecnologias informáticas é estratégica porque elas fazem parte inquestionável do mundo que a rodeia e pela relevância educativa das experiências que lhe pode ser oferecida.

Para Napolitano e Batista (2010, p. 3):

[ao se] utilizar o computador como recurso no período de educação infantil, não prevalece somente o reflexo em disciplinas matemáticas e nas outras. Começa a formar um indivíduo não ouvinte e sim participante e questionador. Não aceitante a resultados preestabelecidos.

Buckingham (2003) considera que os professores devem encorajar a participação das crianças na produção de mídias, pois elas alteram e produzem novos modos de vida e, com isso, também uma nova representação de infância.

A partir do exposto por Amante (2003), Buckingham (2003), Rosado (2006) e Napolitano e Batista (2010), é forçoso reconhecer que reconfigurar o espaço educacional infantil, a partir da inserção das TDIC, requer uma visão ao mesmo tempo abrangente e particular, envolvendo novas maneiras de ensinar e novas formas de aprender, condizentes com o paradigma da sociedade contemporânea, denominada por muitos como "Sociedade do Conhecimento" ${ }^{3}$.

Nesse artigo apresentamos o resultado de pesquisa realizada junto a professoras de educação infantil, de uma cidade do interior de Minas Gerais que teve como objetivo identificar representações sociais (RS) sobre o uso das TDIC na Educação Infantil.

Acredita-se que partindo das representações sociais das professoras seja possível compreender como suas práticas pedagógicas se articulam e se organizam em relação quanto ao uso das TDIC na Educação Infantil e como essas podem originar (ou não) novas práticas

${ }^{3} \mathrm{O}$ pioneiro na utilização desse termo foi Daniel Bell, em The coming of the post-industrial society: A Venture in Social Forecasting. No livro Bell (1976) cunhou a expressão "Sociedade do Conhecimento", reconhecendo que a economia estava saindo de uma era industrial, onde a maioria das pessoas estaria envolvida na produção de coisas, para uma era pós-industrial, na qual o trabalho se via envolvido com a produção de conhecimentos. 


\section{A Educação Infantil na contemporaneidade}

Desde a promulgação da Lei 9.394/96, a LDB, em que se consagrou a nomenclatura Educação Infantil como primeira etapa da Educação Básica e, em seu artigo 29, definiu como sendo finalidade da Educação Infantil, a promoção do desenvolvimento integral da criança até seis anos de idade em um conjunto de diferentes aspectos (físico, psicológico, intelectual e social) complementando a ação da família e da comunidade, se observa um avanço no que diz respeito a este segmento educacional. (BRASIL, 1996). O Parecer CNE/CEB 022/98 reforçou a necessidade de reconhecer as crianças como seres íntegros, que aprendem a ser e conviver com elas mesmas, com os demais e com o meio ambiente de maneira articulada e gradual. Assim, o documento frisa que os objetivos pedagógicos das instituições de Educação Infantil devem buscar a interação das diversas áreas de conhecimento e aspectos da vida cidadã, desenvolvendo conteúdos básicos para a construção de conhecimentos e valores. Dessa maneira, os conhecimentos sobre espaço, tempo, comunicação, expressão, a natureza e as pessoas precisam estar articulados com os cuidados e a educação para a saúde, a sexualidade, a vida familiar e social, o meio ambiente, a cultura, as linguagens, o trabalho, o lazer, a ciência e a tecnologia (BRASIL, 1998).

A partir do estabelecido pela LDB e reafirmado pelo Parecer CNE/CEB 022/98, a Educação Infantil não pode se omitir em proporcionar à criança o contato, a exploração e o domínio educativo das TDIC. Ao utilizar as tecnologias digitais a criança tem a oportunidade de estabelecer novas e ilimitadas formas de interação social, elaborar novas maneiras de aprender e construir conhecimento. Isto acaba evidenciados no próprio Referencial Curricular para a Educação Infantil, RCNEI (1988), em seu terceiro volume, quando aborda o eixo "Conhecimento de Mundo". O documento sugere o inserção do uso do computador na Educação Infantil, reconhecendo-o, portanto, como um recurso material a ser utilizado nas práticas dessa etapa de ensino, com o pretexto de oportunizar o acesso a materiais diferenciados, que podem trazer muitas contribuições para a formação da criança e, consequentemente, sua elaboração de conhecimento de mundo. (BRASIL, 1998).

Torna-se aqui fundamental considerar o exposto por Rocha $(2008$, p. 1)

Embora seja um instrumento fabuloso devido a sua grande capacidade de armazenamento de dados e a facilidade na sua manipulação não se pode esquecer que este equipamento não foi desenvolvido com fins pedagógicos, e por isso é importante que se lance sobre o mesmo um olhar crítico e se busque, face às teorias e práticas pedagógicas, o bom uso desse recurso. $\mathrm{O}$ mesmo só será uma excelente ferramenta, se houver a consciência de que 
possibilitará mais rapidamente o acesso ao conhecimento e não, somente, utilizado como uma máquina de escrever, de entretenimento, de armazenagem de dados. Urge usá-lo como tecnologia a favor de uma educação mais dinâmica, como auxiliadora de professores e alunos, para uma aprendizagem mais consistente, não perdendo de vista que o computador deve ter um uso adequado e significativo.

Sendo assim, acredita-se que, hoje em dia, o processo educativo no universo da criança está a exigir do professor da educação infantil habilidades e competências que vão além do domínio dos conteúdos pedagógicos e atenção a aspectos relacionados ao cuidar e estabelece a necessidade de conhecer, dominar, compreender e identificar como as TDIC podem ser utilizadas como recurso pedagógico para o processo de ensino e de aprendizagem. Esse é um dos grandes desafios da educação infantil e de seus profissionais na contemporaneidade.

Contudo, compreende-se que reconfigurar o espaço educacional infantil a partir da inserção das TDIC requer novas maneiras de ensinar e novas formas de aprender. Um novo fazer que vai se impondo exige da Educação Infantil um constante adaptar-se à realidade social, tanto em relação aos papéis do educador e dos educandos, como na relação entre eles e na maneira de utilização das TDIC no contexto educacional infantil.

\section{As TDIC e o professor de Educação Infantil uma relação em construção?}

Após a Segunda Guerra Mundial teve início uma série de revoluções tecnológicas, que acabaram por culminar na chamada Sociedade de Informação.

Werthein (2000, p. 71) salienta que a expressão 'sociedade da informação" passou a ser utilizada em fins do século XX caracterizando uma sociedade marcada pela informação, com acesso ampliado por conta das TDIC, e já reconhecendo o seu valor. Basta andar pelas ruas e olhar em volta para verificar a quantidade enorme de pessoas que a todo instante utilizam seus celulares conectados à internet, com um número sem fim de aplicativos; as empresas dependem da tecnologia, avançam a automação industrial e tantas outras formas de manifestação da tecnologia na vida das pessoas.

Lévy (1999) vê o período em que se vive atualmente como totalmente permeado pela inovação tecnológica. Dessa maneira, as TDIC, como por exemplo, a Internet, colocam-se como instrumentos indispensáveis, reconhecidas pelo autor como pontos-chave da transformação ao mesmo tempo em que se colocam como elemento inovador e que permite que se criem novos conceitos de interação digital.

Na visão de Levy (1999): 
[...] o atual período permeado pela intervenção tecnológica, a Internet e as ferramentas da TIC têm sido os pontos-chave de transformação, enquanto processo inovador e capaz de estabelecer novos conceitos de interação social. Elas trouxeram à organização social uma maior liberdade, em que o sincronismo e tempo real substituíram o espaço e a interconexão substituiu praticamente a questão do tempo (LEVY 1999, p. 17).

Corroborando com esse pensar, Britto (2011) enfatiza ainda que as TDIC podem se somar à multiplicidade de materiais existentes nos ambientes de aprendizagem, constituindose como (novos) recursos que surgem de forma integrada com outras atividades comuns na Educação Infantil, mas não substituindo as existentes (BRITTO, 2011). Assim, entende-se as TDIC na escola como verdadeiros instrumentos pedagógicos responsáveis por potencializar grandes transformações.

O papel das TDIC no ambiente escolar é proporcionar subsídios para que o processo de ensino-aprendizagem ocorra de forma colaborativa, promovendo a concepção de um novo modelo de ensino e de aprendizagem no qual o educador possa ampliar sua capacidade de ensinar de forma eficaz, dinâmica, estabelecendo uma ponte entre o conhecimento e o educando, tornando-o sujeito ativo nesse processo. Ensinar passa a ser entendido como criar estratégias para a aprendizagem. Assim, exige-se ao educador compreender e utilizar as TDIC visando o aprendizado do aluno e não simplesmente como um meio de transmitir informações, trazendo o novo recurso para perpetuar a velha escola. Uma necessária reinvenção da escola exige que se reconsiderem, de forma substancial, o próprio conceito de aprendizagem e que sejam ressignificados os processos de ensino e que se reconheça que um uso fluente das TDIC passa a ser uma meta social do currículo (DARLING-HAMMOND et al., 2019).

Moran (2000, p. 36) chamou atenção para o fato de que

[...] a educação escolar precisa compreender e incorporar mais as novas linguagens, desvendar os seus códigos, dominar as possibilidades de expressão e as possíveis manipulações. É importante educar para usos democráticos, mais progressistas e participativos das tecnologias que facilitem a educação dos indivíduos.

Sabe-se, contudo, que é um desafio criar e permitir o desenvolvimento de uma nova ação docente onde professores e alunos juntos possam participar de um conjunto de processos para aprender de forma mais criativa, dinâmica e encorajadora, tendo como base o diálogo e a descoberta (BEHRENS, 2000).

A Base Nacional Comum Curricular, BNCC, (BRASIL, 2018), que dá um salto histórico quando reconhece a Educação Infantil como sendo uma etapa essencial na 
escolarização, estabelece os direitos de aprendizagem na Educação Infantil, cabendo destacar dois que, de alguma forma, em maior ou menor grau, guardam alguma relação com as tecnologias:

explorar movimentos, gestos, sons, formas, texturas, cores, palavras, emoções, transformações, relacionamentos, histórias, objetos, elementos da natureza, na escola e fora dela, ampliando seus saberes sobre a cultura, em suas diversas modalidades: as artes, a escrita, a ciência e a tecnologia (BRASIL, 2018, p. 38).

expressar, como sujeito dialógico, criativo e sensível, suas necessidades, emoções, sentimentos, dúvidas, hipóteses, descobertas, opiniões, questionamentos, por meio de diferentes linguagens (BRASIL, 2018, p. 38).

Em vista disso, a construção de novos caminhos para ensinar e aprender na Educação Infantil chama a criança ao papel central do processo de elaboração de significados e o professor se torna mediador entre a criança, a informação e as TDIC construindo-se, assim, educação na contemporaneidade.

Entretanto, Imbérmon (2010, p. 36) alerta para que

[...] o uso das TIC signifique uma transformação educativa que se transforme em melhora, muitas coisas terão que mudar. Muitas estão nas mãos dos próprios professores, que terão que redesenhar seu papel e sua responsabilidade na escola atual. Mas outras tantas escapam de seu controle e se inscrevem na esfera da direção da escola, da administração e da própria sociedade.

Gomes (2013) reconhece que a cultura digital está presente no contexto dos grupos sociais atuais e é importante que a criança contemporânea aprenda a utilizar as TDIC de forma construtiva. No espaço multimídia infantil, celulares, computadores, tablets e outros equipamentos eletrônicos podem ser incluídos no processo de ensino e de aprendizagem, já que esses elementos tecnológicos influenciam a formação das crianças em vários aspectos: desenvolvimento motor, cognitivo, linguagem, conhecimento de mundo e a educação para a diversidade.

Nesse sentido, é Moran (2012, p. 32) quem enfatiza que

a criança também é educada pela mídia, principalmente pela televisão. Aprende a informar-se, a conhecer - os outros, o mundo, a si mesmo - a sentir, a fantasiar, a relaxar, vendo, ouvindo, "tocando" as pessoas na tela, que lhe mostram como viver, ser feliz e infeliz, amar e odiar. A relação com a mídia eletrônica é prazerosa - ninguém obriga - é feita por meio da sedução, da emoção, da exploração sensorial, da narrativa - aprendemos vendo as estórias dos outros e as estórias que os outros nos contam. 
Frente a isso, parece-nos importante considerar a questão do uso das TDIC na prática pedagógica dos professores de Educação Infantil.

Para essa análise o campo teórico das representações sociais permite que se possa compreender como as práticas pedagógicas dos professores se articulam e organizam em relação às suas representações sobre o uso das TDIC na Educação Infantil e como essas poderiam gerar novas práticas.

\section{As contribuições teóricas das representações sociais}

O estudo das representações sociais (RS) possibilita visualizar a realidade de forma multifacetada. Cruzam-se e atravessam-se as construções do senso comum e do senso científico da mesma forma em que se cruzam na realidade cotidiana as ações dos indivíduos.

Em 1961, Serge Moscovici publicou o livro que analisava a forma como os franceses leigos se apropriavam dos conceitos psicanalíticos e como a teoria do campo acadêmico era transformada no processo de apropriação gerando um novo conhecimento. Seu estudo centrava-se na preocupação em desvendar como as pessoas comuns, nas comunicações cotidianas, construíam um conhecimento do senso comum sobre aquilo que seria importante para elas.

Na perspectiva de Moscovici, a dimensão de sujeito social, indivíduo que constrói e recria a realidade em sua relação com o outro, dentro do contexto sócio-histórico-cultural em que o indivíduo atua. As construções do senso comum se tornam "realidades separadas da subjetividade do grupo, das vicissitudes de suas interações e, consequentemente, do tempo e adquirem, portanto, permanência e estabilidade” (MOSCOVICI, 2010, p. 90).

Ainda segundo Moscovici (2003, p. 26), a representação social é “[...] uma modalidade de conhecimento particular que tem por função a elaboração de comportamentos e a comunicação entre os indivíduos". A partir disso torna-se possível dizer que as representações são construídas ao longo do tempo, a partir das interações, são visão da realidade e se manifestam como

[...] um conjunto de conceitos, proposições e explicações originado na vida cotidiana no curso de comunicação interpessoal. Elas são equivalentes, em nossa sociedade, dos mitos e sistemas de crenças das sociedades tradicionais, podem também ser vistas como a versão contemporânea do senso comum (MOSCOVICI, 2001, p. 52).

Assim, de acordo com Moscovici as pessoas estão a todo instante reproduzindo suas representações por meio de atitudes, percepções, comportamentos. Jodelet (2006) reconhece 
que as representações ajudam o indivíduo a se ajustar ao mundo, a lidar com os sucessivos acontecimentos e as transformações que a vida exige porque se relacionam com as experiências particulares e afetivas que os indivíduos têm no mundo. As representações têm significados ricos, carregados de sentidos, que são transformadores das práticas das pessoas ao mesmo tempo em que permitem a compreensão mútua de práticas em ação.

O estudo das representações sociais admite que se possa abarcar como as práticas pedagógicas dos professores se articulam e se organizam em relação às suas representações sobre o uso das TDIC na Educação Infantil e como essas poderiam gerar novas práticas.

\section{Percurso investigativo}

A abordagem metodológica utilizada foi de caráter misto e objetivou identificar as representações sociais de professores que atuavam, em uma escola de Educação Infantil de uma cidade do Estado Minas Gerais.

A cidade pesquisada conta hoje com cerca de 80.000 habitantes e tem se destacado no âmbito da educação, demonstrando a sua vocação na área, uma vez que conta com uma universidade federal, um centro universitário, Instituto Federal, um colégio da Polícia Militar, além de escolas das redes pública e privada.

A pesquisa foi realizada junto a 46 (quarenta e seis) de um total de 73 (setenta e três) professoras da rede municipal urbana de Educação Infantil. Participaram da fase de entrevista 10 (dez) professoras, por adesão voluntária. A opção em investigar professores de Educação Infantil justifica-se pelo fato de que esse segmento de ensino ainda caminha a passos lentos quanto à incorporação das TDIC como recurso pedagógico.

No desenvolvimento da pesquisa, para a coleta de dados foram utilizados um questionário autoaplicável, a técnica de evocação livre e entrevistas semiestruturadas.

A Teoria das Representações Sociais de Moscovici serviu como suporte teórico para conhecer o olhar das professoras sobre o uso das TDIC na Educação Infantil, onde o pesquisador constrói uma metodologia própria a partir da análise dos dados e dos caminhos metodológicos deste referencial teórico. Os dados coletados com o questionário autoaplicável foram tratados estatisticamente através de um software apropriados, enquanto os dados obtidos com a técnica de evocação livre foram submetidos à análise software Evoc $2000^{4}$.

A partir do conhecimento das representações sociais construídas (ou não) pelas

${ }^{4} \mathrm{O}$ EVOC 2000 constitui-se em um conjunto de programas que permitem uma análise de evocações. Ele foi construído na França, por Pierre Verges e seus colaboradores. 
educadoras infantis foi possível compreender o universo dessas professoras, bem como suas concepções, valores, crenças e construções simbólicas nas quais suas práticas educativas estão ancoradas.

\section{Resultados e discussões}

O grupo pesquisado era composto apenas por professoras, quando da realização da pesquisa.

As professoras, pesquisadas, estão concentradas nas faixas etárias inferiores a 49 anos predominando as que têm entre 40 e 49 anos $(32,6 \%)$. Outro fato interessante ao se analisar os dados é a predominância de professoras com tempo de magistério entre 20 e 30 anos (32,3\%) de profissão atuando nesse segmento de educação. Pode-se considerar que no período de formação dessas professoras a discussão sobre o uso das TDIC no contexto educativo ainda era pouco significativa.

O uso das TDIC nos espaços escolares coincide com os comportamentos revelados pelos dados de outros pesquisadores (ARRUDA, 2004; MARINHO, 2007). A pesquisa revelou que $75 \%$ das entrevistadas não utilizavam o computador na sua prática pedagógica. Quando havia, o uso do computador basicamente se restringia ao PowerPoint, com a finalidade de apresentação de histórias infantis, quadros de artistas plásticos e apresentação de pesquisa sobre algum conteúdo estudado.

Quanto ao uso do PowerPoint, uma das entrevistadas o identificou como recurso para a realização de atividades com as crianças em uma perspectiva de demonstração de algum conteúdo.

Às vezes, uso o PowerPoint, pois as crianças podem desenhar, e assim estamos trabalhando a coordenação motora delas. Mas uso muito o PowerPoint para apresentar pinturas de artistas que estamos estudando, ou mesmo para mostrar mais detalhadamente algum tema de nosso projeto (P4).

O uso pelo uso, ou a facilidade e a rapidez de exposição dos dados informacionais, associado à maior facilidade de captação da atenção do aluno, pelo uso de recursos imagéticos, poderia explicar a prevalência do uso de apresentações organizadas em PowerPoint. Entretanto, esse tipo de estratégia evidencia a força das práticas tradicionais em que o professor seleciona, sintetiza, organiza e expõe o conteúdo, isto é, o professor continua no controle do processo de ensino e de aprendizagem. Ao mesmo tempo, demonstra como na 
sociedade atual a palavra necessita do apoio da imagem como recurso motivador e estimulador ao educando.

Bruner (1990) sublinha a importância dos recursos imagéticos para a criança na fase da Educação Infantil, pois a desperta para um sistema de representação visual do mundo, em que a imagem assume uma particular relevância; em que a sensibilidade à cor, movimento, som e luminosidade é particularmente acentuada.

Nas entrevistas, foi reconhecida a importância dada pelas educadoras ao papel das tecnologias e das imagens como motivadoras do interesse do educando em aprender.

[...] eu queria que a escola disponibilizasse os recursos tecnológicos, pois eu poderia propor às crianças "Gente, quero mostrar uma pesquisa de ciências. Vamos ver o animalzinho aqui no computador". Essa disponibilidade e uso do recurso faz com que a criança viaje no imaginário (P2).

[...] tem muita coisa no mundo exterior à escola que as crianças podem conhecer e interagir através desta tecnologia, coisas muito boas de geografia, ciências por exemplo. Usando as tecnologias, eles veem a imagem muitas vezes real do que está sendo estudado. E, para a criança, imagem e movimento são tudo (P10).

Durante as entrevistas, percebeu-se que as educadoras têm o costume de levar o próprio computador (notebook) para a escola, com o objetivo de apresentar alguma informação aos alunos. Dados do CETIC (2018) revelam que 50\% dos professores de escolas públicas brasileiras urbanas levam seu próprio notebook para a sala de aula. Esse dado é importante pois aponta que ainda não há uma disponibilidade suficiente de recursos tecnológicos digitais nas instituições públicas de educação, incluindo a infantil.

Apesar das dificuldades em relação ao acesso aos recursos tecnológicos e a necessidade de transportarem seus computadores pessoais para o ambiente da sala de aula, várias entrevistadas levantaram possibilidades de utilização das tecnologias na elaboração de estratégias didáticas superando formas tradicionais de trabalhar.

Nós usamos muito papel, se tivermos computadores para as crianças realizarem as atividades, seria muito mais interessante tanto para eles como para nós, professoras. Haveria mais envolvimento e interesse. No computador, as crianças teriam acesso ao programa educativo de acordo com a faixa etária e poderiam ir desenvolvendo o tema e, à medida que se sentissem seguras e preparadas, avançariam. Nós, professoras, as ajudaríamos em alguma dificuldade quanto ao conteúdo e manuseio do computador. Estaríamos trabalhando juntos (P7). 
O papel do educador no contexto descrito na entrevista da P7 sustenta a escolha de estratégias em que o professor atue como mediador no processo de ensino e de aprendizagem. Mediador, facilitador, significando uma atitude e comportamento, por parte do docente, incentivador ou motivador da aprendizagem, que colabora ativamente para que o aprendiz chegue aos seus objetivos. Característica que, na atualidade, é exigida e esperada dos educadores desde a Educação Infantil.

Quanto a tecnologia digital foi possível identificar que as professoras reconhecem as TDIC como ferramentas importantes para a educação das crianças de Educação Infantil. A propósito o grupo pesquisado demonstrou vontade e interesse em utilizar as TDIC como recurso em suas aulas. Esse movimento é compreendido com o estudo das representações sociais.

\section{Representações sociais (RS) das professoras}

O software Evoc 2000 permitiu a categorização dos termos associados à evocação "Uso do Computador na Educação Infantil" buscando-se, fundamentalmente, a análise da frequência que permitiu a determinação dos elementos que compunham o núcleo central da representação, que constitui a parte coletiva da representação. O núcleo central das RS foi identificado no quadro das quatro casas do sistema de representações do grupo investigado, utilizando-se uma frequência mínima de 5, intermediária de 9 e ordem média de 2,0 (Figura 1).

É relevante esclarecer que ao núcleo central das RS são atribuídas as seguintes características: é marcado pela memória coletiva, refletindo as condições sócio históricas e os valores do grupo; consiste a base comum, consensual, coletivamente partilhada das representações, definindo a homogeneidade do grupo social; é estável, coerente, resistente à mudança, assegurando assim a continuidade e a permanência da representação; é relativamente pouco sensível ao contexto social e material imediato no qual a representação vem a se manifestar. Suas funções são gerar o significado básico da representação e determinar a organização global de todos os elementos.

Com base nessas características e a partir dos dados referentes à evocação "uso do computador na Educação Infantil" foram identificados no núcleo central os termos "inovação" e "interessante", termos que congregam os principais e mais relevantes significados do uso TDIC na Educação Infantil na atualidade, pelas pesquisadas. 
Figura 1 - Quadro de quatro casas para uso do computador na Educação Infantil

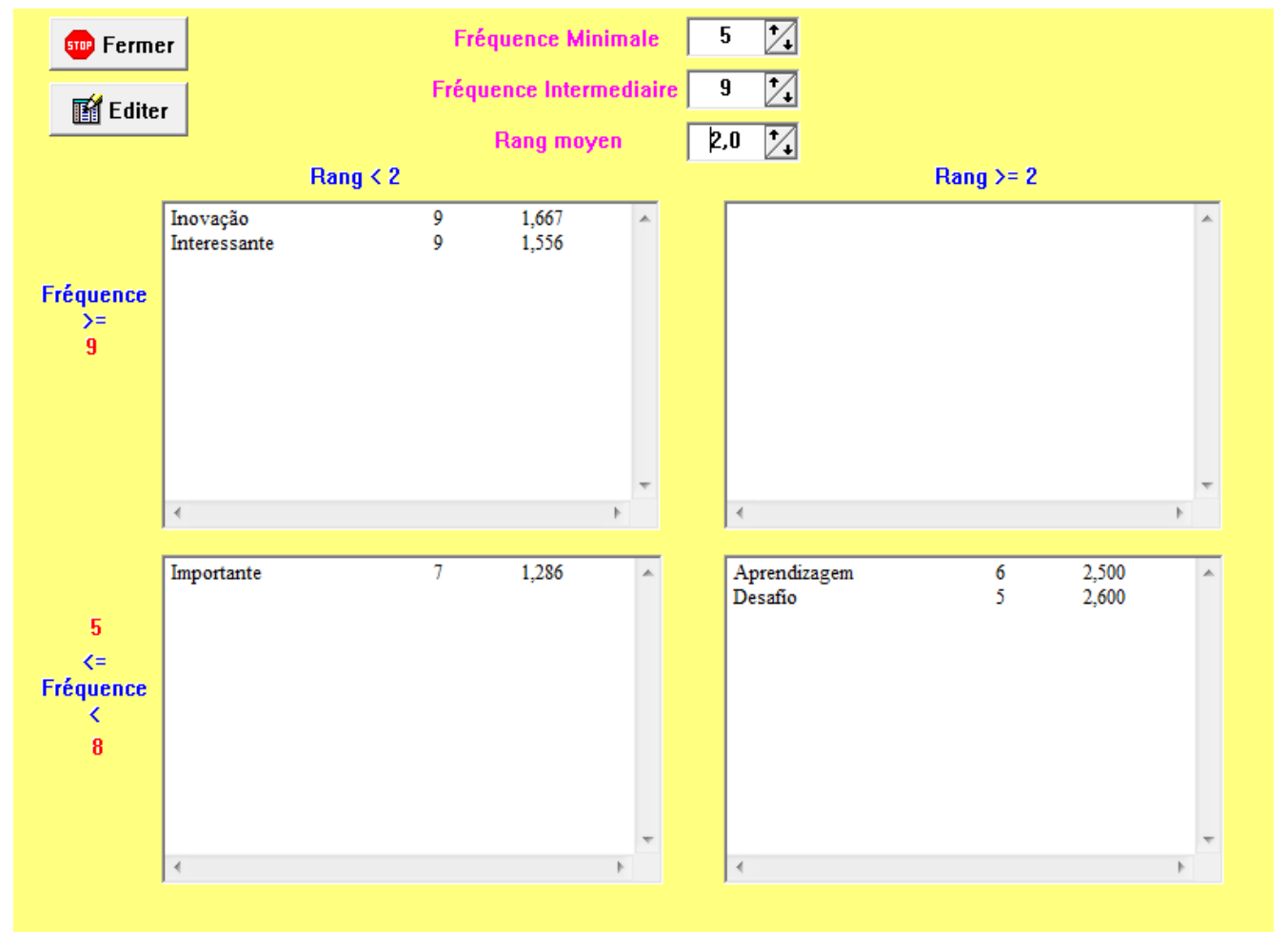

Fonte: dados da pesquisa

Sabe-se que as crianças da Educação Infantil possuem uma vivência com as TDIC extraescolar, o que faz com que, cheguem à escola conhecendo algo dessas tecnologias.

[...] sempre alguma criança traz o seu computador de casa. Percebo o quanto a turma fica envolvida e interessada com tudo o que envolve o computador (P6).

[...] quando você vai contar uma história para uma criança a primeira coisa que você escuta é ela te falando "ouvi essa história no computador com o meu pai". Ai você vai desenvolver uma brincadeira "eu brinquei disso com o meu pai no computador. Eu fiz isso com a minha mãe no computador" (P9).

Como estão presentes no contexto social infantil e as crianças demonstram familiaridade com elas, as TDIC tornam-se recurso "interessante", representação identificada no núcleo central, que precisa ser agregado ao trabalho desenvolvido em sala de aula na atualidade. Amante (2003) reforça a familiaridade da criança, desde pequena, com as tecnologias informáticas ao enfatizar que elas fazem parte inquestionável do mundo que a rodeia e pela relevância educativa das experiências que lhes pode ser oferecida. 
Porém, para que as TDIC sejam incorporadas às práticas educativas agregando-lhes valor, exige-se ao professor a inovação (pedagógica), termo também identificado no núcleo central das representações sociais das professoras.

Considerando as impressões de Carbonell (2002), a inovação, em uma definição abrangente, é entendida como um conjunto de intervenções, decisões e processos que, com certo grau de intencionalidade e sistematização, tratam de alterar atitudes, culturas, ideias, conteúdos, modelos e práticas pedagógicas.

Entretanto, percebeu-se nas entrevistas com as professoras que suas práticas pedagógicas ainda se encontram atreladas a um modelo tradicional de Educação Infantil. Esse modelo acaba fundamentando a ação educativa na escola, ainda que haja o concurso das TDIC, no que podemos caracterizar como uma subutilização das tecnologias digitais, na inovação conservadora (CYSNEIROS, 1999).

[...] pesquisar atividades de outras professoras para fazer com as crianças, desenhos, músicas que outras escolas já utilizaram em apresentações e usar na minha escola com as minhas crianças (P5).

[...] tirar atividades, procurar na internet. Festa Junina, dancinha, ai eu vou na internet procurar exemplos de danças. Lembrancinhas para o Dia das Mães eu uso o computador também. Eu acho que isso até se tivesse na escola poderia deixar livre para eles: "Vamos escolher uma lembrancinha para o Dia das Mães?”. Eles mesmos (P7).

[...] pesquisar atividades de outras professoras para fazer com as crianças, desenhos, músicas que outras escolas já utilizaram em apresentações e usar na minha escola com as minhas crianças (P1).

A força das representações já construídas contribui para que as professoras tenham dificuldades de ver em si mesmas a possibilidade recriadora. Assim, recorrem ao poder do outro de refazer, recriar, fazer uma coisa nova.

Eu penso em mudar, mas não sei como, penso em transformar minha prática pedagógica, mas não consigo pensar, não consigo imaginar de que maneira. Gostaria até de ter um auxilio mesmo, para saber melhor minha prática. Eu sei pesquisar, imprimir coisas para trabalhar com as crianças, isto é, fazer o que é básico na internet, mas não sei o que mais de pedagógico que eu poderia fazer lá (P6).

Portanto, para que haja inovação (pedagógica) é necessário que haja a criação de projetos pedagógicos que incorporem as TDIC como recurso pedagógico. Essa incorporação potencializa uma ruptura nas práticas pedagógicas tradicionais, impelindo a Educação Infantil e seus professores a estabelecerem inovações (pedagógicas), necessárias ao contexto social 
vigente, o que vai exigir do professor aprendizagem para utilizaras TDIC como recurso pedagógico.

A necessidade de aprendizagem é reforçada pelos dois termos identificados no sistema periférico: "desafio" e "aprendizagem" que reforçam o termo inovação identificado no núcleo central das representações.

É importante compreender que o sistema periférico é constituído pelos demais elementos da representação, que, provendo a "[...] interface entre a realidade concreta e o sistema central." (ABRIC, I993, p. 79), atualizam e contextualizam as determinações normativas e consensuais deste último, resultando na mobilidade, na flexibilidade e na expressão individualizada das representações sociais. $\mathrm{O}$ sistema periférico apresenta as seguintes características: permite a integração de experiências e histórias próprias de cada indivíduo; dá suporte à a heterogeneidade do grupo e às contradições; é evolutivo e se mostra sensível ao contexto imediato (ABRIC, I993). Enfim, suas funções consistem, em termos atuais e cotidianos, na adaptação à realidade concreta e na diferenciação do conteúdo da representação e, em termos históricos, na proteção do sistema central.

Considerando o papel do sistema periférico e a partir dos termos identificados no quadro das quatro casas para esse sistema, pode-se dizer que para que haja inovação (núcleo central), é necessário que o professor construa uma aprendizagem para saber utilizar as TDIC como recurso pedagógico.

[...] nós, professoras, não temos o preparo para trabalhar com ele em sala de aula. Eu gosto muito de poder trabalhar com um objeto que faz parte da vida das crianças. Mas, às vezes, me sinto perdida, sem saber o que fazer e como fazer no computador (P2).

[...] A insegurança por não saber como trabalhar com o computador. A falta de formação e capacitação para um trabalho pedagógico com os computadores e com a internet, como tem com outros materiais (P8).

[...] o professor se preparando estaria apto para poder exercer, para poder trabalhar com computação (P4).

[...] ao mesmo tempo em que é um desafio. A gente tem que aprender a trabalhar a ferramenta, utilizar o computador para poder passar para eles. Se tivesse um laboratório de informática aqui, a gente teria que ter um curso para a gente poder passar as coisas para eles (P6).

O despreparo e a consequentemente insegurança apontados pelas professoras para utilizar as TDIC no contexto de sala de aula são resultantes da ausência ou insuficiência de 
formação inicial e continuada para utilizar tais ferramentas digitais como recurso pedagógico, exigindo-lhes uma aprendizagem.

Essa nova aprendizagem torna-se, assim, para as professoras, um desafio, termo identificado no sistema periférico (Figura 1). Mais do que instrumentalizar o uso das TDIC, a aprendizagem deverá provocar uma ressignificação da concepção do que é ensinar e aprender e do que é ensinar e aprender com o uso das TDIC o que implica a constituição de outras/novas práticas pedagógicas, exige inovação.

A sociedade em si, espera e cobra, cobra que a educação esteja em perfeita sintonia com a realidade e os anseios do mundo contemporâneo. Assim, discutir, questionar e rever a forma de atuar dos professores, na busca de (re)significar as práticas diante do surgimento de uma tecnologia que modifica a possibilidade de acesso ao saber quando comparada às tecnologias já utilizadas na escola, exige formação, seja no tempo da inicial, ou seja na continuada.

[...] as TDIC são um conhecimento necessário, precisamos trabalhar de maneira diferente. Precisamos pensar que na sociedade em que vivemos, estamos envolvidos pelo computador e a internet e que, saber usar com criatividade e criticidade, vai fazer diferença. E esse aprendizado deve acontecer na escola, desde muito pequenos. Precisamos estar preparados para trabalhar com o computador na sala de aula. Acho que vamos ter que trilhar novos caminhos na Educação Infantil (P2).

[...] o computador [...] está exigindo da gente, professor, uma nova maneira de trabalhar, de conversar e de interagir com as crianças (P8).

Os depoimentos ilustram a importância do processo de formação do professor para o uso das TDIC como recurso pedagógico. Nos cursos de formação o professor teria a possibilidade de construir novas representações, em sintonia com os anseios e necessidades da sociedade vigente.

A vastidão de significados e possibilidades de utilização das TDIC evidencia um terreno fértil para sua utilização na Educação Infantil. As tecnologias digitais significam inovação, são interessantes, representam um desafio inclusive para a formação do professor ao exigir aprendizagem do próprio educador, já que em sua formação esse tema não esteve no centro das preocupações pedagógicas.

Diante desses elementos: "inovação", "interessante", "aprendizagem" e "desafio" que compõem o quadro das quatro casas sobre o uso do computador na Educação Infantil pode-se compreender que para o grupo pesquisado construir uma prática pedagógica com as TDIC 
exige uma linguagem contemporânea e um aprimoramento da prática docente. Encontra-se aí um dos maiores desafios aos educadores infantis na contemporaneidade.

\section{Algumas considerações no fechamento}

A partir dos anos de 1990 as tecnologias digitais chegaram à escola, como reflexo do Neoliberalismo e do Capitalismo que se desenvolveu no complexo mundo globalizado. Entretanto, a educação ainda apresenta dificuldades em acompanhar este avanço. Dentre os fatores que dificultam esse progresso encontra-se na opinião do grupo pesquisado, neste estudo, falta de formação para o uso das tecnologias digitais no contexto escolar, ausência dos recursos tecnológicos digitais necessários na escola, dentre outros.

Viu-se que o uso do computador na Educação Infantil é reconhecido, pelo grupo pesquisado, como recurso pedagógico válido, uma vez que a cultura digital faz parte do universo infantil contemporâneo. Entretanto, a utilização das TDIC como ferramenta pedagógica exige práticas de atuação para as quais as professoras, envolvidas nesta pesquisa, ainda não se sentem preparadas, o que torna fundamental uma formação continuada, mediada pelas TDIC como recurso e ferramenta pedagógica.

$\mathrm{Na}$ construção de inovações (pedagógicas) os cursos de formação de professores são imprescindíveis, tanto para que a Educação Infantil seja discutida, (re)pensada e (re)construída, de forma significativa e criativa, como para propiciar e estimular a reflexão sobre a própria prática do professor, criando condições para que novas maneiras de atuação possam ser construídas, considerando as necessidades e ferramentas disponíveis na sociedade atual. E a utilização pedagógica das TDIC só será apoderada pelos professores em função de todo um conjunto de representações do que é a Educação Infantil, do que são as próprias tecnologias e de seu papel educativo na contemporaneidade.

Reconhecendo a Educação Infantil um espaço privilegiado para as vivências das crianças de até cinco anos, crê-se que importante que o professor observe, discuta e reflita sobre as práticas e vivências, com as tecnologias digitais, realizadas pelas crianças. $\mathrm{O}$ professor deve se entender como um mediador, cujo desafio é fazer com que a criança faça o uso adequado das TDIC, como meio para desenvolver diferentes capacidades e ampliar seus conhecimentos e conquistas.

Para as professoras, que participaram dessa pesquisa, as TDIC são reconhecidas como ferramentas importantes para a educação das crianças de Educação Infantil e o grupo pesquisado demostrou vontade e interesse em utilizar as tecnologias digitais como recurso em 
suas aulas. Entretanto, sinalizaram também vários desafios para a utilização das TDIC na Educação Infantil dentre eles o despreparo do professor para seu uso como ferramenta pedagógica, a carência de recursos digitais dentro das escolas e, até mesmo, uma ausência de incentivo por parte a equipe escolar e dos órgãos públicos, que não oferecem o respaldo necessário para que se viabilize o uso das TDIC com os alunos. Superar esses e outros desafios exige comprometimento e envolvimento de toda a sociedade, revisão profunda dos currículos de formação e das escolas de Educação Infantil, além de um repensar sobre a concepção de infância, de educação infantil, de tempo/espaço e da própria prática docente.

Portanto, revelar as representações desse grupo de professoras sobre o uso do computador na Educação Infantil foi uma forma de contribuir para que futuros pesquisadores e professores possam se posicionar de forma crítica e reflexiva frente às demandas com as TDIC.

Apropriar-se pedagogicamente dos recursos tecnológicos para produzir conhecimentos, tendo em vista seu significado como tecnologia de inserção social, como canal de comunicação e acesso à informação, exige esforços que considerem os reais sujeitos sociais, suas crenças, seus valores, os conhecimentos produzidos no cotidiano como tão concretos, importantes e geradores de transformações sociais quanto os conhecimentos produzidos na academia, nas instituições de pesquisa, nas empresas de inovação tecnológica.

Muito há ainda a ser pesquisado em relação às representações sociais dos professores sobre o uso das TDIC na Educação Infantil, especialmente após uma pandemia ter provocado mudanças na escola, na medida em que esta foi para as casas, com a adoção do ensino remoto emergencial. $\mathrm{O}$ ensino remoto foi adotado por algumas escolas como estratégia para cumprimento da carga horária mínima obrigatória prevista na LDB para a Educação Infantil. Essa adoção, mesmo na ausência de uma previsão legal, de ao menos uma normativa para oferta de uma espécie educação a distância neste segmento educação escolar, ainda que em uma emergência, exigiu aos professores, às crianças e até mesmo às famílias um uso intensivo das TDIC, o que sem dúvida acarretou dificuldades, gerou transtornos. Entretanto é importante destacar que para as professoras que participaram dessa pesquisa, ainda que antes da pandemia, o uso das tecnologias digitais nesse segmento de ensino já era percebido de forma positiva e sua utilização já deveria estar em processo de construção. No período póspandemia é possível que as escolas, por seus gestores e professores, e até mesmo os sistemas escolares repensem a integração curricular das TDIC na Educação Infantil e não só nela. 
AGRADECIMENTOS: A pesquisa contou com apoio da FAPEMIG, CAPES e CNPq.

\section{REFERÊNCIAS}

ABRIC, J. C. Central system, peripheral system: their functions and roles in the dynamics of social representations. Papers on Social Representations, v. 2, n. 2, p. 75-78, 1993.

AMANTE, L. A integração das novas tecnologias no pré-escolar: um estudo de caso. 2003. Tese (Doutoramento em Ciências da Educação) - Universidade Aberta, Lisboa, 2003.

ARRUDA, E. Ciberprofessor: novas tecnologias, ensino e trabalho docente. Belo Horizonte: Autêntica, 2004.

BEHRENS, M. A. Aparecida. Projetos de aprendizagem colaborativa num paradigma emergente. In: MORAN, J. M. Novas tecnologias e mediação pedagógica. Campinas: Papirus, 2000.

BELL. D. The coming of the post-industrial society: a venture in social forecasting. New York: Basic Books, 1976.

BRASIL. Constituição. Constituição da República Federativa do Brasil de 1988. Brasília: Senado Federal, 1988.

BRASIL. Lei n. 9.394, de 20 de dezembro de 1996. Estabelece as diretrizes e bases da educação nacional. Diário Oficial da União, Brasília, 23 dez. 1996. Disponível em: https://www2.camara.leg.br/legin/fed/lei/1996/lei-9394-20-dezembro-1996-362578publicacaooriginal-1-pl.html. Acesso em: 25 jun. 2020.

BRASIL. Ministério da Educação e do Desporto. Referencial curricular nacional para a educação infantil. v. 3. Brasília: MEC/Secretaria de Educação Fundamental, 1998.

BRASIL. Ministério da Educação. Base Nacional Comum Curricular: educação é a base. Brasília: MEC, 2018. Disponível em

http://basenacionalcomum.mec.gov.br/images/BNCC_EI_EF_110518_versaofinal_site.pdf. Acesso em 08 ago. 2020.

BRASIL. Ministério da Educação. Conselho Nacional de Educação. Parecer CNE/CEB n. 22/1998. Diretrizes Curriculares Nacionais para a Educação Infantil. Diário Oficial da União, Brasília, 23 mar. 1998. Disponível em:

http://portal.mec.gov.br/dmdocuments/parecer_ceb_22.98.pdf. Acesso em: 25 jun. 2020.

BRITTO, R. As TIC em educação pré-escolar: utilização pelos educadores de infância e crianças. Málaga: Universidade de Málaga, 2011. Disponível em:

https://core.ac.uk/reader/62687866. Acesso em: 25 jun. 2020.

BRUNER, J. Actos de significado: para uma psicologia cultural. Lisboa: Edições 70, 1990. 
BUCKINGHAM, D. Media education: literacy, learning and contemporary culture. Cambridge: Polity Press, 2003.

CARBONELL, J. A aventura de inovar: a mudança na escola. Porto Alegre: Artmed, 2002.

CENTRO DE ESTUDOS SOBRE AS TECNOLOGIAS DA INFORMAÇÃO E DA COMUNICAÇÃO. TIC Educação - 2019. São Paulo: Comitê Gestor da Internet do Brasil, 2014. Disponível em: https://cetic.br/pt/tics/educacao/2019/escolas-urbanas-professores/. Acesso em: 03 jun. 2020.

CYSNEIROS, P. G. Novas tecnologias na sala de aula: melhoria do ensino ou inovação conservadora. Informática Educativa, v. 12, n. 1, p. 11-24, 1999.

DARLING-HAMMOND, L. et al. Metas e objetivos educacionais: o desenvolvimento de uma visão curricular para o ensino. In: DARLING-HAMMOND, L.; BRANSFORD, J. (Org.). Preparando professores para um mundo em transformação o que devem aprender e estar aptos a fazer. Porto Alegre: Penso, 2019.

GOMES, S. S. Brincar em Tempos Digitais. Presença Pedagógica, Belo Horizonte, n. 113, p. 44-51, 2013.

JODELET, D. Loucuras e representações sociais. Trad. Lucy Magalhães. Petrópolis: Vozes, 2006.

LEVY, P. Cibercultura. São Paulo: 34, 1999.

MARINHO, S. P. P. A tecno-ausência na formação inicial do professor da educação básica na visão de docentes de licenciaturas. In: SCHWART, C. M. et al. (Org.). Desafios da educação básica e pesquisa em educação. Vitória: EDUFES, 2007. p. 177-199.

MARINHO, S. P. P. Representações sociais de professores da Educação Básica sobre a internet e a Web 2.0 na aprendizagem: condição para a integração curricular da web na Educação Básica. Relatório de pesquisa. Belo Horizonte: PUC Minas, 2014.

MOSCOVICI, S. Representações sociais investigações em psicologia social. 7. ed. Petrópolis, Rio de Janeiro: Vozes. 2010.

NAPOLITANO, L. R.; BATISTA, F. F. A ciência da computação aplicada no período de educação infantil. Revista Iberoamericana de Educación. ISSN: 1681-5653. Disponível em: https://rieoei.org/historico/deloslectores/518Napolitano.pdf. Acesso em: 19 nov. 2016.

PÉREZ GÓMEZ, A. I. Educação na Era Digital: a escola educativa. Porto Alegre: Penso, 2015.

ROBINSON, K.; ARONICA, L. Escolas criativas: a revolução que está transformando a educação. Porto Alegre: Penso, 2019.

ROCHA, S. S. D. O uso do computador na educação: a informática educativa. Revista Espaço Acadêmico, n. 85, jun. 2008. 


\section{Como referenciar este artigo}

OLIVEIRA, N. M. de; MARINHO, S. P. P. Tecnologias digitais na Educação Infantil: representações sociais de professoras. Revista Ibero-Americana de Estudos em Educação, Araraquara, v. 15, n. 4, p. 2094-2114, out./dez. 2020. e-ISSN: 1982-5587. DOI: https://doi.org/10.21723/riaee.v15i4.14068

Submetido em: $30 / 04 / 2020$

Aprovado em: 19/08/2020

Publicado em: 30/08/2020 